\title{
Enhanced Eryptosis in Glucose-6-Phosphate Dehydrogenase Deficiency
}

\author{
Ghada Bouguerra ${ }^{a, b} \quad$ Khaoula Talbib,c Nawel Trabelsi ${ }^{b, c} \quad$ Dorra Chaouachib \\ Imen Boudriga ${ }^{b}$ Salem Abbès ${ }^{a, b}$ Samia Menifa,b \\ aUniversité de Tunis El Manar, Faculté de Médecine de Tunis, Tunis, Tunisie, bUniversité de Tunis El \\ Manar, Laboratoire d'Hématologie Moléculaire et Cellulaire, Institut Pasteur de Tunis, Tunis, Tunisie, \\ ‘Université de Tunis El Manar, Faculté des Sciences de Tunis, Tunis, Tunisie
}

\section{Key Words}

Eryptosis $•$ Phosphatidylserine exposure $\cdot$ Anemia $•$ G6PD deficiency $•$ Oxidative stress

\begin{abstract}
Background/Aims: Defects in the Glucose-6-Phosphate Dehydrogenase (G6PD) enzyme enhance cellular oxidative damage, thus impairing erythrocytes and radically shortening their lifespan. We aimed to study programmed erythrocyte cell death in G6PD-deficient patients, describe the molecular genetics basis of G6PD and investigate phenotype-genotype correlations. Methods: We explored eryptosis using the annexin V-binding assay, taken as an indicator of PS exposure at the erythrocyte surface. We assessed reactive oxygen species (ROS) production, intracellular calcium concentrations and ceramide formation at the cell surface. Prior to and following treatments, cells were analyzed by flow cytometry. Finally, we explored G6PD gene mutations through PCR-Sanger sequencing. Results: Before stimulation, PS-exposing erythrocytes were significantly higher in G6PD-deficient patients than in healthy volunteers. This was paralleled by a significant increase in reactive oxygen species production, suggesting that oxidative stress is the main trigger of PS exposure in G6PDdeficient erythrocytes. Five previously described mutations were detected in our patients. Two genotypes correlated with a significantly higher percentage of PS-exposing cells. Conclusion: Our study uncovers a novel effect detected in G6PD-deficient erythrocytes which is cell membrane scrambling with PS translocation to the erythrocyte surface. Our findings shed a light on the mechanisms of premature erythrocyte clearance in G6PD deficiency.
\end{abstract}

(C) 2021 The Author(s). Published by Cell Physiol Biochem Press GmbH\&Co. KG

\section{Introduction}

Glucose-6-Phosphate Dehydrogenase (G6PD) deficiency is the most common hereditary enzymopathy worldwide [1]. Due to the disease's genotypic heterogeneity [2], clinical manifestations vary from mild to severe syndromes such as neonatal jaundice (NNJ) [3], favism [4], congenital non-spherocytic hemolytic anemia (CNSHA) [5] and drug 


\section{Cellular Physiology Cell Physiol Biochem 2021;55:761-772 \\ \begin{tabular}{ll|l} 
and Biochemistry Published online: 11 December 2021 & $\begin{array}{l}\text { C } 2021 \text { The Author(s). Published by } \\
\text { Cell Physiol Biochem Press GmbH\&Co. KG }\end{array}$ \\
\hline
\end{tabular} \\ Bouguerra et al.: Eryptosis in G6PD Deficiency}

or infection-induced hemolytic anemia (DIHA and IIHA respectively) [6]. Predominantly, the pathophysiology in G6PD deficiency is characterized by episodes of hemolysis which are triggered either by the exposure to oxidative stress through infection [7], the ingestion of certain foods such as fava beans [8] or oxidative treatments such as the antimalarial Primaquine [9].

As G6PD catalyzes the first step in the pentose phosphate pathway (PPP), the enzyme not only controls the generation of the only reducing power in erythrocytes in the form of reduced nicotinamide adenine dinucleotide phosphate (NADPH) [10] but also sustains a constant supply of the reduced form of the antioxidant enzyme Glutathione (GSH) [11]. GSH plays a crucial role in maintaining membrane integrity as well as maintaining hemoglobin $(\mathrm{Hb})$ at its functional state by neutralizing reactive oxygen species (ROS) such as free radicals, hydrogen peroxide, and other oxidative species produced as a result of regular oxygen metabolism in erythrocytes [12]. Consequently, a decrease in G6PD levels jeopardizes the erythrocyte's antioxidant machinery, which in turn, enhances cellular oxidative damage [13], thus impairing erythrocytes [14].

A housekeeping gene, located on the X chromosome, encodes the G6PD enzyme [15]. So far, more than 200 genetic variants were described, in association with the aforementioned wide range of clinical manifestations [16]. In regions such as Tunisia, where the deficiency is endemic [17], predominant variants include the African variant A- (G6PD:c.376A>G, G6PD:c.202G>A) [18, 19], classified as a type III deficiency by the World Health Organization and associated with both CNSHA and DIHA, and the Mediterranean variant B(G6PD:c.563C >T), classified as a type II deficiency and associated with favism and NNJ [17]. Evidence suggests that both variants are associated with a premature cellular breakdown through severe shortening of erythrocyte half-life from 60 to 22 days [20].

The premature cellular breakdown of erythrocytes could be a consequence of either hemolysis or eryptosis [21]. Eryptosis is a process of erythrocyte programmed cell death, which is characterized by biochemical and morphological stigmas mimicking the apoptosis of nucleated cells [22]. Biochemical hallmarks of eryptosis include calcium $\left(\mathrm{Ca}^{2+}\right)$ entry in the cell with an increase of cytosolic $\mathrm{Ca}^{2+}$ activity $\left(\left[\mathrm{Ca}^{2+}\right]_{\mathrm{i}}\right)[23]$, alteration of intracellular ion homeostasis [24], activation of cysteine proteases such as $\mu$-calpain [25] and caspase 3 [26] as well as the generation of free radicals paralleled by the inactivation of antioxidant enzymes [27]. During this cellular death process, morphological changes include cell shrinkage [28], membrane blebbing, and exposure of the phospholipid phosphatidylserine (PS) at the outer leaflet [29]. Under physiological conditions, PS is retained within the inner membrane leaflet through the ATP-dependent aminophospholipid translocase (APLT), thus ensuring an asymmetrical phospholipid distribution through the membrane [30]. PSexposing erythrocytes are recognized by macrophages belonging to the endothelial system through their vitronectin receptors, then rapidly and efficiently cleared from the circulation $[31,32]$.

Although an enhanced sensitivity to eryptosis was, previously reported in G6PD deficiency [33], there is as yet no consistent data on PS exposure, nor a consensus on the underlying mechanisms of premature programmed erythrocyte cell death. Furthermore, there were no thorough examinations of the relationship between the nature of the molecular defects and the enhanced eryptosis in G6PD.

In this study, we explore eryptosis in G6PD-deficient patients through the quantification of PS exposure at the cell surface. We further examine the signaling pathways orchestrating the enhanced eryptosis in this pathological context. Finally, we study the G6PD gene in order to investigate the potential correlation between G6PD genetic variants and enhanced eryptosis in G6PD-deficient patients. 


\section{Cellular Physiology Cell Physiol Biochem 2021;55:761-772

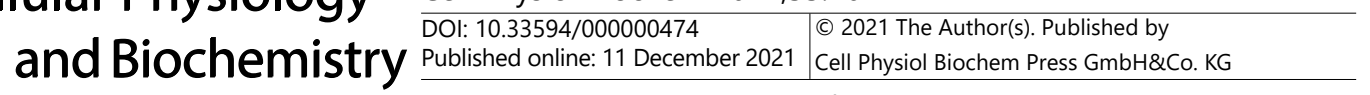 \\ Bouguerra et al.: Eryptosis in G6PD Deficiency}

\section{Materials and Methods}

Study Subjects

The study involved 19 subjects diagnosed with G6PD deficiency. Patients were chosen based on age (older than a year), transfusion status (no history of transfusion), and the absence of concomitant hematological disorders such as sickle cell anemia, thalassemia, and PK deficiency. The control group included 21 healthy volunteers. All patients and healthy volunteers gave their informed written consent per the recommendations of the ethical committee of the Pasteur Institute of Tunis and the declaration of Helsinki.

\section{Hematological explorations}

Blood samples were collected in EDTA-containing tubes. Complete blood counts (CBC) were obtained through a Pentra 60C+ analyzer (ABX Diagnostics, Montpelier, France).

Hemoglobin fractions analysis was carried out through capillary electrophoresis using a Capillarys 2 FLEX Piercing analyzer (Sebia, Evry, France).

G6PD activity was measured through quantitative spectrophotometric analysis of the rate of NADPH production from NADP as previously described [34]. G6PD activity was considered normal when ranging between $5.26 \mathrm{IU} / \mathrm{g}$ of $\mathrm{Hb}$ and $7.94 \mathrm{IU} / \mathrm{g}$ of $\mathrm{Hb}$.

\section{Flow Cytometry}

Flow cytometry experimental procedures were performed as previously described by Jemaà et. al [35]. Data acquisition was carried out on 50,000 cells for each sample. For all experiments, fluorescence was measured with an excitation wavelength of $488 \mathrm{~nm}$ and an emission wavelength of $530 \mathrm{~nm}$ in a logarithmic scale using the flow cytometer FACS Canto II (BD Biosciences, France). Forward scatter (FSC) and Side Scatter (SSC) were determined on a linear scale. An arbitrary threshold was set at 5000 in order to exclude cellular debris.

Pretreatment of Samples. Blood samples were centrifuged at 500xg for 20 minutes and the leucocytes and platelets containing supernatant was discarded. Erythrocytes were resuspended in Ringer solution (pH 7.4) containing $125 \mathrm{mM} \mathrm{NaCl}, 5 \mathrm{mM} \mathrm{KCl}, 1 \mathrm{mM} \mathrm{MgSO}{ }_{4}, 32 \mathrm{mM} \mathrm{N}$-2-hydroxyethylpiperazine- $\mathrm{N}-2$ ethanesulfonic acid (HEPES), $5 \mathrm{mM}$ glucose and $1 \mathrm{mM} \mathrm{CaCl}_{2}$ at $0.4 \%$ hematocrit. All incubations were performed at $37^{\circ} \mathrm{C}$.

Where indicated, oxidative stress was induced by the addition of $0.3 \mathrm{mM}$ tetra-butyl-hydroxyperoxide (TBHP, Sigma Aldrich, Germany) to Ringer solution, followed by the incubation of samples for 1 hour at $37^{\circ} \mathrm{C}$. Similarly, opening of $\mathrm{Ca}^{2+}$ channels was induced by the addition of $1 \mu \mathrm{M}$ of the calcium ionophore Ionomycin (Sigma Aldrich, Germany) in dimethyl sulfoxide (DMSO) to Ringer solution, followed by the incubation of samples for 2 hours at $37^{\circ} \mathrm{C}$.

Annexin-V binding assay. Annexin-V binding was determined in freshly-drawn blood. For this purpose, a suspension of $150 \mu \mathrm{l}$ from each sample was centrifuged at $1600 \mathrm{rpm}$ for $3 \mathrm{~min}$. Cells were subsequently stained with annexin-V-FITC (1:200 dilution in Ringer solution containing $5 \mathrm{mM} \mathrm{CaCl}_{2}$; BD Biosciences, France) and incubated at $37^{\circ} \mathrm{C}$ for $15 \mathrm{~min}$ under protection from light.

A marker was placed in order to separate annexin-V-binding cells from control cells.

Assessment of intracellular $\mathrm{Ca}^{2+}$. Intracellular Calcium was determined through Fluo3/AM assay. Cells were washed in Ringer solution containing $5 \mathrm{mM} \mathrm{CaCl}$, pelleted and then loaded with $5 \mu \mathrm{M}$ Fluo3/AM (Sigma Aldrich, Germany). Pellets were incubated at $37^{\circ} \mathrm{C}$ for $30 \mathrm{~min}$ then resuspended in Ringer solution.

Ceramide formation at the cell surface. Cells were stained for 1 hour at $37^{\circ} \mathrm{C}$ with $1 \mu \mathrm{g} / \mathrm{ml}$ monoclonal anti-ceramide antibody (clone MID 15B4, Sigma Aldrich, Germany) in PBS containing $0.1 \%$ bovine serum albumin BSA at a dilution of 1:10. The samples were washed twice with PBS-BSA. Subsequently, the cells were stained for $30 \mathrm{~min}$ with polyclonal fluorescein isothiocyanate (FITC) conjugated goat anti-mouse IgG and IgM antibody (BD Biosciences, Belgium) diluted 1:50 in PBS-BSA. Unbound secondary antibody was removed by washing twice with PBS-BSA. 


\section{Cellular Physiology Cell Physiol Biochem 2021;55:761-772

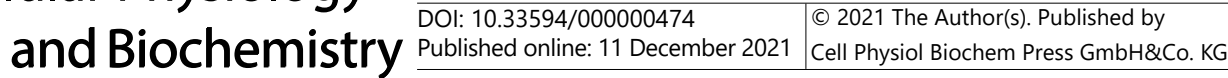 \\ Bouguerra et al.: Eryptosis in G6PD Deficiency}

Reactive Oxygen Species quantification. Oxidative stress was determined using 2',7'-dichlorodihydrofluorescein diacetate (DCFDA). After incubation, a $150 \mu$ l suspension was washed in Ringer solution and then stained with DCFDA (Thermo Fisher, France) in Ringer solution containing DCFDA at a final concentration of $10 \mu \mathrm{M}$. Erythrocytes were incubated at $37^{\circ} \mathrm{C}$ for $30 \mathrm{~min}$ in the dark and then washed three times in Ringer solution.

\section{PCR-Sanger sequencing}

Genomic DNA was extracted from peripheral blood using the standard phenol-chloroform method [36]. Mutations spanning the G6PD gene were determined by polymerase chain reaction (PCR) followed by Sanger Sequencing. A screening of the entire coding sequence of the gene (exons 2 to13) was carried out using the primer pairs listed in Table 1. PCR was carried-out in a $25 \mu \mathrm{l}$ mixture containing $50 \mu \mathrm{g}$ of genomic DNA; 10X PCR buffer; $10 \mathrm{mM}$ dNTPs; $20 \mu \mathrm{M}$ of each primer; $25 \mathrm{mM} \mathrm{MgCl}_{2}$; 5 IU Taq polymerase and ultrapure $\mathrm{H}_{2} \mathrm{O}$. Reaction conditions were as follows: $95^{\circ} \mathrm{C}$ for $5 \mathrm{~min}$, followed by 35 cycles of denaturation at $95^{\circ} \mathrm{C}$ for $30 \mathrm{sec}$, annealing at $58^{\circ} \mathrm{C}$ for $30 \mathrm{Sec}$ (exon 13), at $60^{\circ} \mathrm{C}$ for $45 \mathrm{sec}$ (exon2, 6-7 and 8), at $62^{\circ} \mathrm{C}$ for $30 \mathrm{sec}$ (exon $10-12$ ), at $65^{\circ} \mathrm{C}$ for $30 \mathrm{sec}$ (exon 3-4, 5 and 9), and an extension at $72^{\circ} \mathrm{C}$ for $45 \mathrm{sec}$. The final extension was performed at $72^{\circ} \mathrm{C}$ for $7 \mathrm{~min}$.

\section{Statistics}

Data are expressed as arithmetic means \pm Standard Deviation (SD). In order to determine statistical significance between groups, Mann-Whitney test, or ANOVA test with Tukey's test as post-test were performed as appropriate using GraphPad Prism version 5.00 (GraphPad Software, USA). For all experiments, $\mathrm{n}$ denotes the number of individuals and the threshold of significance was set at $\mathrm{p}<0.05$.

\section{Results}

\section{Hematological data}

Except for two individuals who had microcytosis, most patients showed normal hematological indices, as shown in Table 2.

\section{Flow cytometry}

Erythrocytes, entering eryptosis, were identified through the annexin V-binding assay, which directly reflected the percentage of phosphatidylserine exposure at the cell surface. As depicted in Fig. 1 (A-B), the percentage of annexin V-binding erythrocytes was significantly higher in cells taken from G6PD-deficient patients $(1.38 \pm 1.08)$ than in cells drawn from healthy controls $(0.64 \pm 0.29)$.

To determine erythrocytes' cell volume, forward scatter was measured. Similarly, we assessed cell density through the study of side scatter (Fig. 2 (A-D)). Despite the slight decrease noted in cells from G6PD-deficient patients $(55,142 \pm 10,273)$, there was no significant difference in forward scatter compared to erythrocytes from the control group $(66,875 \pm 25,853)$. However, a marked and significant decrease in SSC was noted in cells from G6PD-deficient patients scatters $(14,342 \pm 7493)$, compared to the control group $(29,085 \pm 19,891)$.

Table 1. Primer sequences used in the molecular exploration of the G6P gene

\begin{tabular}{lccc}
\hline Primer & Sequence (5' to 3') & Size & Range \\
\hline G6PD-Trl2F & TCTCCCATGCTCCAGGTMATTG & \multirow{2}{*}{662 bp } & Exon 2 \\
G6PD-Trl2R & CACCAGGTAGAVCCGGGATGAT & & \\
G6PD_Trl3-4F & CAWGYTTGTGGCCCAGTAGTGA & 764 bp & Exons 3-4 \\
G6PD_Trl3-4R & TTCAGCCCCATCTTAGCAGCTC & & \\
G6PD_Trl5F & GAGCTGCTAAGATGGGGCTGAA & 686 bp & Exon 5 \\
G6PD_Trl5R & GCATTCAAAACCAGCCAGAGGA & & \\
G6PD_Trl6-7F & CTGGGAGGGCGTCTGAATGAT & 728 bp & Exons 6-7 \\
G6PD_Trl6-7R & RTGGRGTGCTTGGCTGTGTAGG & & \\
G6PD_Trl8F & CTGGAAGACAAGGGGKATCAKG & 629 bp & Exon 8 \\
G6PD_Trl8R & TGGGRTRCAGGGATGACTGTG & & \\
G6PD_Trl9F & CAGTCATCCCTGYAYCCCAACT & 342 bp & Exon 9 \\
G6PD_Trl9R & ACCAGYGCGTGAGTGTCTCAGT & & \\
G6PD_Trl10-12F & ACTGAGACACTCACGCRCTGGT & 769 bp & Exons 10-12 \\
G6PD_Trl10-12R & GGTGGAGRAGAGGCATGAGGTAG & & \\
G6PD_Trl13F & GATTGAGCWGGAGAAGCCYAAG & 642 bp & Exon 13 \\
G6PD_Trl13R & CAAGGCCACAGGCAGATTCTCT & & \\
\hline
\end{tabular}


Table 2. Hematological data of healthy volunteers and G6PD-deficient patients. ${ }^{* * *} \mathrm{p}<0.001$ indicates a significate difference in the G6PD-deficient group compared to healthy volunteers

\begin{tabular}{|c|c|c|c|}
\hline Parameters & Control & G6PD-deficient patients & P value \\
\hline Sex & $\begin{array}{l}10 \text { Female } \\
11 \text { Male }\end{array}$ & $\begin{array}{c}5 \text { Female } \\
14 \text { Male }\end{array}$ & - \\
\hline Age (median, range) & $29[19-60]$ & $4[1-74]$ & - \\
\hline G6PD (UI/g of Hb) & $6.77 \pm 1.27$ & $4.28 \pm 0.51$ & $\mathrm{p}<0.001^{* * *}$ \\
\hline Red Blood Cells $\left(10^{6} / \mathrm{mm}^{3}\right)$ & $4.99 \pm 0.16$ & $4.53 \pm 0.44$ & ns \\
\hline Hemoglobin $(\mathrm{g} / \mathrm{dL})$ & $14.8 \pm 1.03$ & $12.01 \pm 0.90$ & $\mathrm{p}<0.001^{* * *}$ \\
\hline Hematocrit (\%) & $41.36 \pm 4.40$ & $37.47 \pm 2.64$ & ns \\
\hline Mean Cellular Volume (fL) & $88.97 \pm 5.61$ & $37.47 \pm 2.64$ & ns \\
\hline Mean Cellular Hemoglobin (pg) & $28.28 \pm 0.12$ & $26.89 \pm 1.59$ & ns \\
\hline Mean Cellular Hemoglobin Concentration (g/dL) & $33.28 \pm 2.20$ & $31.64 \pm 1.20$ & ns \\
\hline Reticulocytes (\%) & $1.19 \pm 0.20$ & $0.35 \pm 0.01$ & ns \\
\hline
\end{tabular}

Fig. 1. Phosphatidylserine exposure in G6PD-deficient patients. A. Arithmetic means \pm SEM $(\mathrm{n}=$ 21 - 19) of the percentage of Annexin V-binding erythrocytes in freshly drawn blood from healthy individuals (controls, black circles) and G6PD-deficient patients (black triangles). ${ }^{* * *}(\mathrm{p}<0.001)$ indicates significant difference from healthy volunteers. (Mann-

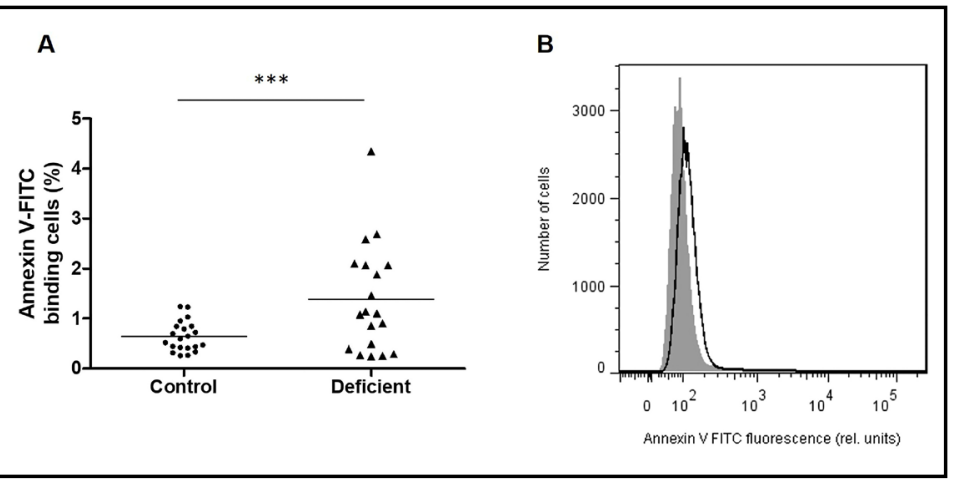
Whitney test). B. Original histograms of Annexin-V-binding of erythrocytes taken from healthy subjects (grey area) and G6PD-deficient patients (black line).

Because calcium is the main actor of significant morphological and biochemical changes during eryptosis, we investigated the intracellular calcium content in G6PDdeficient erythrocytes through a Fluo3/am assay. Fluo3/am-dependent fluorescence was measured in erythrocytes before and following the treatment of fresh erythrocytes with the calcium ionophore ionomycin. As shown in Fig. 3 (A-C), Fluo3/AM-dependent fluorescence was lower in G6PD-deficient cells $(180.2 \pm 74.02)$ than in cells from healthy individuals $(210.9 \pm 124.1)$. This decrease in fluorescence only reaches a statistical difference following the treatment with ionomycin $(1 \mu \mathrm{M})$ in Ringer solution for 2 hours at $37^{\circ} \mathrm{C}$. Indeed, we detected a significantly lower Fluo3/AM-dependent fluorescence in patients (391.1 \pm 183.7) compared to that measured in controls $(615.7 \pm 383)$.

We designed a third set of experiments to determine the intracellular content in reactive oxygen species as well as the involvement of extracellular oxidative stress in enhancing eryptosis in G6PD deficiency. DCFDA-dependent fluorescence, taken as a measure of intracellular ROS content, was measured before and after exposure to the oxidant TBHP. Fig. 4 (A-C) shows that there seems to be no significant difference in DCFDA fluorescence between cells taken from G6PD-deficient patients (419.3 \pm 165.4$)$ and cells taken from healthy individuals $(379.9 \pm 131)$. However, following the exposure to $0.3 \mathrm{mM}$ TBHP for 1 hour, a significantly higher DCFDA fluorescence was recorded in cells from deficient patients than in cells from controls ( $1784 \pm 476.7$ and $1396 \pm 268.5$ respectively).

Finally, ceramide formation at the cell surface was quantified using FITC-labeled antibodies. As shown in Fig. 5 (A-B), ceramide abundance was slightly lower in G6PD-deficient cells than in control cells (respectively $127.5 \pm 39.78$ and $131.8 \pm 37.88$ ), a difference that did not reach statistical difference. 
Fig. 2. Forward and Side scatter in G6PD-deficient patients. A, B. Arithmetic means \pm SEM ( $n=21$ - 19) of erythrocyte Forward scatter and Side scatter in freshly drawn blood from healthy individuals (white) and G6PD-deficient patients (black). ${ }^{*}(\mathrm{p}<0.05)$ indicates significant difference from healthy volunteers. (MannWhitney test). C, D. Original histograms of Forward scatter and side scatter of erythrocytes taken from healthy subjects (grey area) and G6PD-deficient patients (black line).

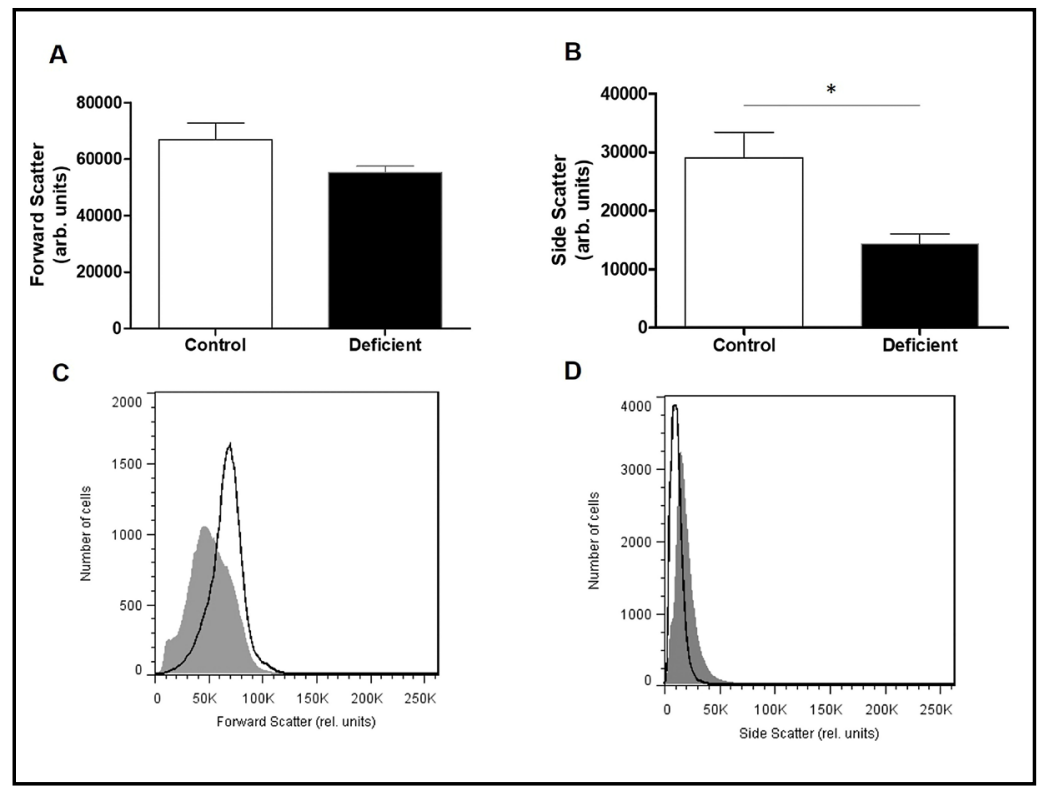

Fig. 3. Intracellular $\mathrm{Ca}^{2+}$ activity in G6PD-deficient erythrocytes. A. Arithmetic means \pm SEM ( $n=21$ - 19) of Fluo3-AM fluorescence in freshly drawn blood from healthy individuals (white) and G6PD-deficient patients (black) prior to and following treatment with ionomycin $(1 \mu \mathrm{M}){ }^{*}(\mathrm{p}<0.05)$ indicates significant difference from healthy volunteers (Mann-Whitney test). B, C. Original histograms of Fluo3-AM fluorescence of erythrocytes taken from healthy subjects (grey area)

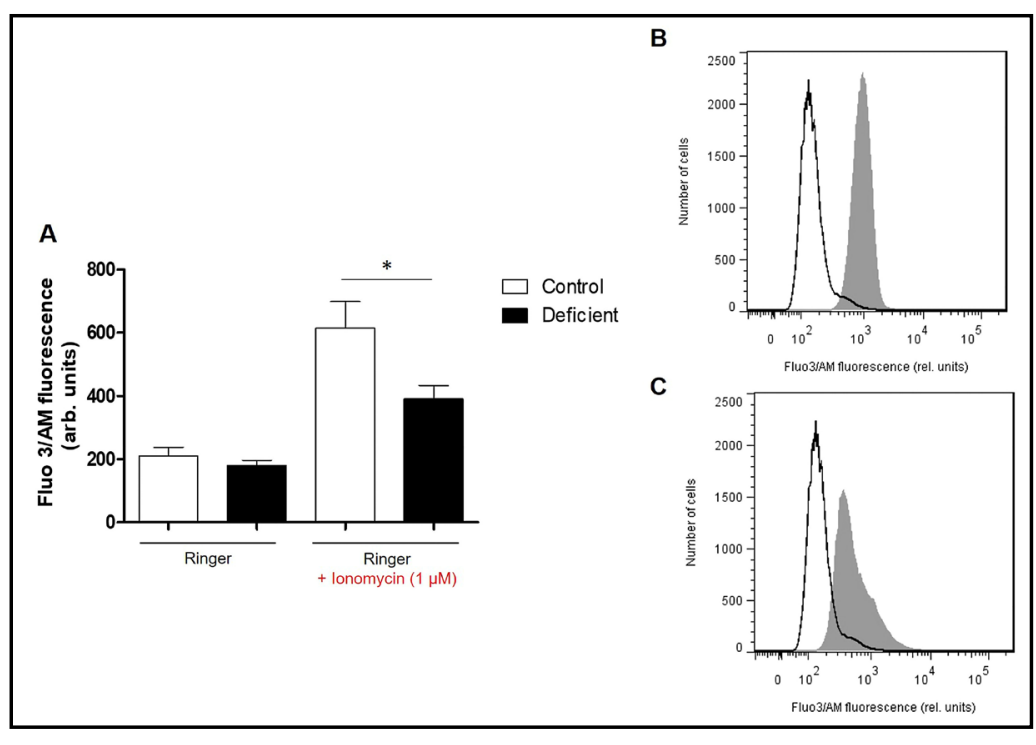
and G6PD-deficient patients (black line) prior to and following treatment with ionomycin $(1 \mu \mathrm{M})$.

\section{Molecular Findings}

DNA sequencing of the $G 6 P D$ gene revealed a total of five previously-described mutations, accounting for the enzymatic deficiency in our subjects. The most frequently-encountered mutation, G6PD: c.202G>A, associated with the African variant A-, was found in eleven patients (0.53), including eight hemizygous males as well as in three heterozygous females. The second mutation accounting for the African variant G6PD: c.376A $>\mathrm{G}$, was found in a total of eight patients (0.33), five of whom were hemizygous males, and three were heterozygous females.

The G6PD: c.563C>T mutation, associated with the Mediterranean variant, was only found in two males in the hemizygous form (0.13).

Furthermore, DNA sequencing revealed the presence of two rare mutations. The first was a substitution in exon 11, G6PD: c.1311C>T, which was only found in the heterozygous form in three females. The second was an intronic mutation, G6PD: c.1365-13T $>C$, encountered 
Fig. 4. ROS activity in G6PDdeficient erythrocytes. A. Arithmetic means \pm SEM ( $\mathrm{n}=21$ - 19) of DCFDAdependent fluorescence in freshly drawn blood from healthy individuals (white) and G6PD-deficient patients (black) prior to and following treatment with $0.3 \mathrm{mM}$ TBHP. ${ }^{* *}(\mathrm{p}<0.01)$ indicates significant difference from healthy volunteers. (MannWhitney test). B, C. Original histograms of DCFDAdependent fluorescence of erythrocytes taken from healthy subjects (grey area)

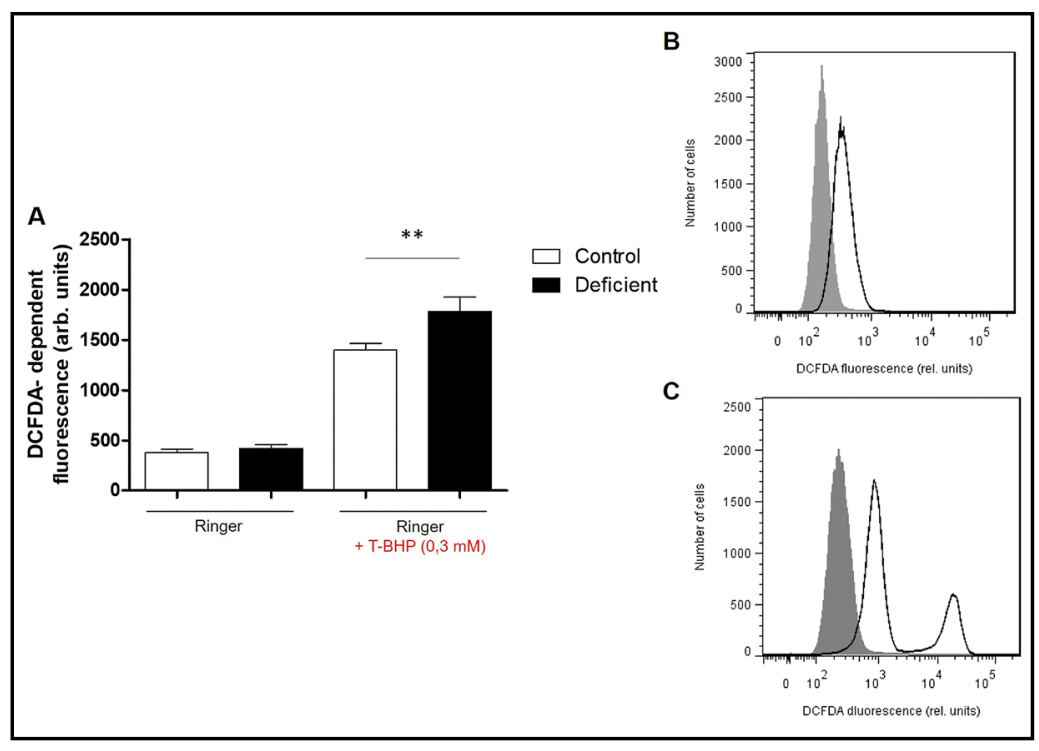
and G6PD-deficient patients (black line) prior to and following treatment with $0.3 \mathrm{mM}$ TBHP.

Fig. 5. Ceramide quantification at the cell surface of G6PD-deficient erythrocytes. Arithmetic means \pm SEM ( $\mathrm{n}=21$ - 19) of anti-ceramide dependent fluorescence in freshly drawn blood from healthy individuals (white) and G6PD-deficient patients (black). (Mann-Whitney test).

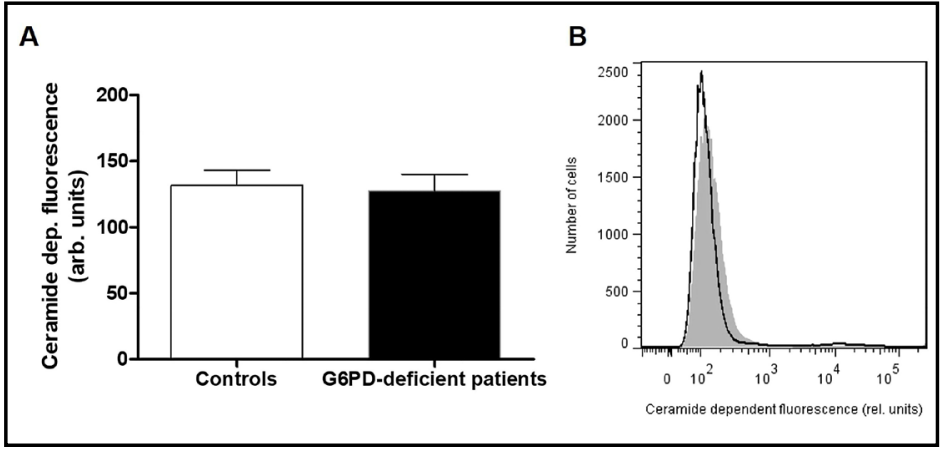

in one heterozygous female, one homozygous female, and three hemizygous males. Allele frequencies, calculated only for male patients, are summarized in Table 3.

No mutations spanning the entire coding sequence of the G6PD gene were detected in three deficient patients, all-male.

\section{Phenotype-Genotype correlations}

Due to lionization, female patients present with heterogeneous erythrocytes. To further explore the impact of G6PD genetic variants on eryptosis, we excluded female patients from further analysis. We separated male G6PD-deficient patients into four groups according to their genotypes. The first group encompassed seven patients who presented with the African variant A-. The second included three patients presenting with the African variant as well as the c.1311 C>T mutation. The third group included only two patients who presented with the Mediterranean variant B-. Finally, the fourth group included four patients presenting with the intronic mutation c.1365-13T $>$ C.

Compared to erythrocytes taken from healthy individuals, cells taken from patients belonging to the first and the fourth group presented a significantly higher percentage of annexin-V binding cells (Fig. 6). Furthermore, cells taken from the fourth group showed the highest percentage of annexin- $\mathrm{V}$ binding cells, compared to all groups, and seem to present significantly higher annexin-V binding cells when compared to the A- group. 


\section{Cellular Physiology Cell Physiol Biochem 2021;55:761-772 \begin{tabular}{ll|l} 
and Biochemistry & $\begin{array}{l}\text { DOl: 10.33594/000000474 } \\
\text { Published online: 11 December 2021 }\end{array}$ & $\begin{array}{l}\text { C 2021 The Author(s). Published by } \\
\text { Cell Physiol Biochem Press GmbH\&Co. KG }\end{array}$ \\
\cline { 2 - 3 } & Bom
\end{tabular} \\ Bouguerra et al.: Eryptosis in G6PD Deficiency}

Table 3. Allele frequencies of G6PD mutations in G6PD-deficient male patients

\begin{tabular}{|c|c|c|c|c|c|c|c|}
\hline $\begin{array}{l}\text { Detected } \\
\text { variant }\end{array}$ & Mutation & Location & $\begin{array}{c}\text { cDNA } \\
\text { nucleotide } \\
\text { substitution }\end{array}$ & Codon (a.a. substitution) & $\begin{array}{c}\text { Homozygote } \\
\text { (n) }\end{array}$ & $\begin{array}{l}\text { Heterozygote } \\
\text { (n) }\end{array}$ & $\begin{array}{l}\text { Hemizygote } \\
\text { (n) }\end{array}$ \\
\hline \multirow[t]{2}{*}{ G6PD A- } & G6PD:c.202G>A & Exon 4 & $202 \mathrm{G}>\mathrm{A}$ & 68 (Val>Met) & - & 3 & 8 \\
\hline & G6PD:c.376A>G & Exon 5 & $376 \mathrm{~A}>\mathrm{G}$ & 126 (Asn>Asp) & - & 3 & 5 \\
\hline G6PD B- & G6PD:c.563C>T & Exon 6 & $563 \mathrm{C}>\mathrm{T}$ & 188 (Ser>Phe) & - & - & 2 \\
\hline \multirow[t]{2}{*}{ Other } & G6PD:c.1311C>T & Exon 11 & $1311 \mathrm{C}>\mathrm{T}$ & $437 \mathrm{Y}>\mathrm{Y}$ silent & - & 3 & - \\
\hline & G6PD:c.1365-13T>C & Intron 11 & $93 \mathrm{~T}>\mathrm{C}$ & NA & 1 & 1 & 3 \\
\hline
\end{tabular}

Fig. 6. Phosphatidylserine exposure according to genotypes in G6PD-deficient patients. Arithmetic means \pm SEM of the percentage of Annexin V-binding erythrocytes in freshly drawn blood from healthy individuals (white), G6PD-deficient patients presenting with the A-variant (vertical white stripes), the A- variant associated to the c.1311 C>T mutation (horizontal white stripes), the B- variant (black) and the intronic mutation c.1365-13T>C (slanted white lines). ${ }^{* * *}(\mathrm{p}<0.001)$ and ${ }^{* *}(\mathrm{p}<0.01)$ indicate significant difference from healthy volunteers. $\#(p<0.05)$ indicates significant difference from the A- group. ANOVA test.

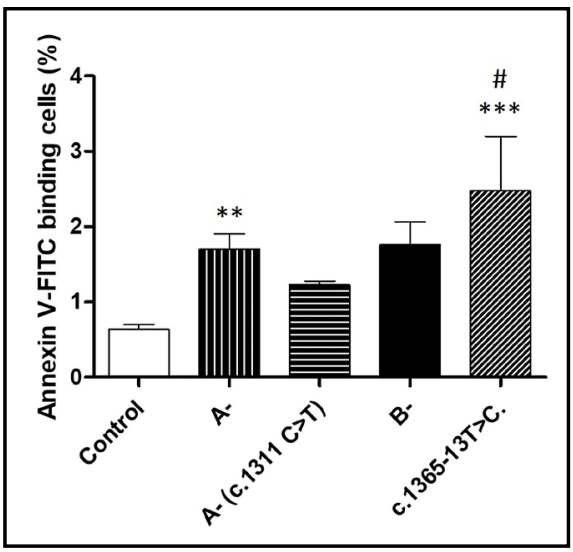

\section{Discussion}

Our study demonstrates enhanced eryptosis in G6PD-deficient erythrocytes through significant cell membrane scrambling in non-stimulated cells. Using the annexin V-binding assay, we established that non-stimulated erythrocytes significantly expose PS at the membrane surface, thus leading to membrane scrambling.

Flow cytometry data shows that the loss of membrane asymmetry in G6PD-deficient erythrocytes is paralleled by a significant increase in cell density, which could be explained by the exit of osmotically obliged water following the activation of $\mathrm{K}^{+}$channels (the Gardos effect). The latter phenomenon is usually paralleled by a significant decrease in forward scatter, reflecting cell shrinkage during eryptosis. However, we found that although the decrease in cell size was notable in samples retrieved from G6PD-deficient patients, it did not reach statistical significance.

This result could be due to the absence of a prominent intracellular calcium concentration in unstimulated cells, which would activate the $\mathrm{Ca}^{2+}$-sensitive $\mathrm{K}^{+}$channels. Furthermore, our data show that calcium levels were significantly lower in G6PD-deficient erythrocytes than in cells taken from healthy volunteers.

So far, the role of calcium in eryptosis signaling, in the context of G6PD deficiency, remains greatly debated. While a study of forty (40) G6PD-deficient patients by Feng et., al [37] confirms the absence of a significant role of calcium in eryptosis signaling, even following stimulation, a recent study by Hertz et al. [38], shows significantly increased intracellular calcium concentrations in fresh G6PD deficient erythrocytes.

Other mechanisms involved in eryptosis signaling include oxidative stress. Whether intracellular or extracellular, oxidative stress participates in erythrocyte death in G6PD deficiency. Due to the instability of the active form of the G6PD enzyme, reactive oxygen species escape the diminished antioxidant defenses and thrive in this defective milieu [39]. Through DCFDA staining, we quantified ROS production in stimulated and unstimulated cells. Although increased compared to the control group, ROS production in erythrocytes from G6PD-deficient patients did not reach statistical significance. Yet, when exposed to an oxidant ( $0.3 \mathrm{mM}$ TBHP for 1 hour), ROS production significantly increases in erythrocytes taken from G6PD deficient patients. 


\section{Cellular Physiology Cell Physiol Biochem 2021;55:761-772 \\ \begin{tabular}{ll|l} 
and Biochemistry & $\begin{array}{l}\text { DOl: 10.33594/000000474 } \\
\text { Published online: 11 December 2021 }\end{array}$ & $\begin{array}{l}\text { C } 2021 \text { The Author(s). Published by } \\
\text { Cell Physiol Biochem Press GmbH\&Co. KG }\end{array}$
\end{tabular} \\ Bouguerra et al.: Eryptosis in G6PD Deficiency}

This phenomenon could be due to the episodic nature of erythrocyte death in G6PD deficiency. Indeed, none of the patients suffered from a chronic hemolytic syndrome. They were referred to our laboratory based on the physician's recommendations, mainly following the ingestion of fava beans. By the time erythrocyte cell death was assessed, the hemolytic episode had already passed, which would explain the baseline levels ROS in non-stimulated erythrocytes.

Our results suggest that ROS seem to be the chief mediators of enhanced eryptosis in G6PD-deficient erythrocytes. In this case, the primary signaling pathway triggered by oxidative stress would bypass calcium signaling. The increase in intracellular calcium concentration is not always sufficient on its own to disrupt the phospholipid asymmetry regulation machinery such as the aminophospholipid translocase (APLT), the membrane scramblases, and floppases. Consequently, PS externalization does not automatically correlate with the increase in cytosolic calcium concentration [40].

Along those lines, the study by Mandal et al., describes a calcium-independent-Fasmediated signaling pathway involving caspases in erythrocytes. The pathway is orchestrated by Caspase 8 , which is activated following the exposure of erythrocytes to oxidative stress [26]. In particular, Mandal and al.'s results suggest that the correlation between the activation of caspases and the externalization of PS could be due either to the inhibition of the activity of flippase through the proteolytic cleavage of the membrane transporter by caspase- 3 or indirectly by affecting other regulators of floppases [41].

Further investigations into the mechanisms of eryptosis led us to the quantification of ceramide abundance at the cell surface. Using FITC-labeled anti-ceramide antibodies, we showed that ceramide tended to be lower in cells from patients than in controls, a difference that did not reach statistical significance. Thus, it is highly likely that ceramide is involved in eryptosis signaling in G6PD deficiency.

Finally, we investigated the potential correlation between G6PD genetic variants and enhanced eryptosis in deficient male patients. Patients presenting with the A- variant showed a significant percentage of Annexin-binding cells compared to the control group. From a structural point of view, in vitro folding of the A- variant was shown to produce partially folded polypeptides that do not undergo the dimerization needed for the enzymatic activity of G6PD [42]. The latter decreases to about 5 to $10 \%$ of normal activity which would explain the enhanced eryptosis in A- cells.

Erythrocytes from the group of G6PD-deficient patients carrying the c.1365-13T $>C$ intronic mutation presented with the highest percentage of PS-exposure, a rather surprising result. Indeed, c.1365-13T $>C$ is a non-synonymous single nucleotide variant that does not seem to have any deleterious consequences on the G6PD protein. However, Sirdah et al., previously described a possible association for this variant, in conjunction with the $3^{\prime} \mathrm{UTR}$ c. $^{*}+357 \mathrm{~A}>\mathrm{G}$ (rs1050757) mutation, with G6PD deficiency [43]. Therefore, further molecular explorations of the 3'UTR region of the G6PD gene need to be performed on our study subjects. Similarly, further investigations of the 3'UTR and the promoter regions need to be completed on the three G6PD-deficient patients who did not present any defects in the explored G6PD gene sequences.

\section{Conclusion}

In conclusion, enhanced eryptosis effectively contributes to anemia in G6PD deficiency. Furthermore, the genetic variants associated with the enzyme deficiency seem to contribute to the degree of enhanced eryptosis. Our findings shed a light on the mechanisms of premature erythrocyte clearance in G6PD deficiency and suggest a potential use of the annexin V-binding assay in the biological monitoring of G6PD-deficient patients. 


\section{Cellular Physiology Cell Physiol Biochem 2021;55:761-772

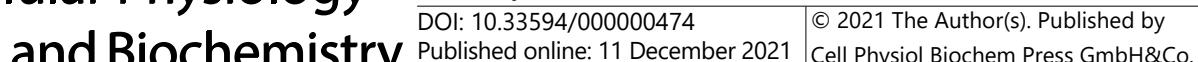 \\ Published online: 11 December 2021 Cell Physiol Biochem Press GmbH\&Co. KG \\ Bouguerra et al.: Eryptosis in G6PD Deficiency}

\section{Acknowledgements}

\section{Author Contributions}

B.G. designed the project, carried out the experiments and wrote the manuscript. T.K. assisted with in vitro cell experiments and data collection. T.N. participated in flow cytometry data analysis and critical discussion of the study. C.D. and B.I. assisted in the collection of samples and G6PD enzymatic activity measurements. A.S. supervised in vitro experiments and manuscript preparation. M.S. supervised and assisted in critical discussions of the study.

\section{Funding Sources}

This research did not receive any specific grant from funding agencies in the public, commercial, or not-for-profit sectors.

\section{Statement of Ethics}

All patients and healthy volunteers gave their informed written consent per the recommendations of the ethical committee of the Pasteur Institute of Tunis and the declaration of Helsinki.

\section{Disclosure Statement}

The authors declare that no conflicts of interest exist.

\section{References}

1 Beutler E: Glucose-6-phosphate dehydrogenase deficiency. In Hemolytic anemia in disorders of red cell metabolism, Springer, Boston, MA, 1978, pp. 23-167.

2 Beutler E: The genetics of glucose-6-phosphate dehydrogenase deficiency. Semin Hematol 1990;27:137164.

3 Kaplan M, Hammerman C, Vreman HJ, Stevenson DK, Beutler E: Acute hemolysis and severe neonatal hyperbilirubinemia in glucose-6-phosphate dehydrogenase-deficient heterozygotes. J Pediatr 2001;139:137-140.

4 Meloni T, Forteleoni G, Dore A, Cutillo S: Favism and Hemolytic Anemia in Glucose-6-Phosphate Dehydrogenase-Deficient Subjects in North Sardinia. Acta Haematol 1983;70:83-90.

5 Fiorelli G, Martinez di Montemuros F, Cappellini MD: Chronic non-spherocytic haemolytic disorders associated with glucose-6-phosphate dehydrogenase variants. Best Pract Res Clin Haematol 2000;13:3955 .

6 Beutler E: The Hemolytic Effect of Primaquine and Related Compounds: a Review. Blood 1959;14:103-139.

7 Siddiqui T, Khan AH: Hepatitis A and Cytomegalovirus Infection Precipitating Acute Hemolysis in Glucose6-Phosphate Dehydrogenase Deficiency. Mil Med 1998;163:434-435.

8 Kattamis CA, Kyriazakou M, Chaidas S: Favism: clinical and biochemical data. J Med Genet 1969;6:34-41.

9 Carson PE, Flanagan CL, Ickes CE, Alving AS: Enzymatic Deficiency in Primaquine-Sensitive Erythrocytes. Science 1956;124:484-485.

10 Kruger NJ, von Schaewen A: The oxidative pentose phosphate pathway: structure and organisation. Curr Opin Plant Biol 2003;6:236-246.

11 Pandolfi PP, Sonati F, Rivi R, Mason P, Grosveld F, Luzzatto L: Targeted disruption of the housekeeping gene encoding glucose 6-phosphate dehydrogenase (G6PD): G6PD is dispensable for pentose synthesis but essential for defense against oxidative stress. EMBO J 1995;14:5209-5215.

12 Çimen MYB: Free radical metabolism in human erythrocytes. Clinica Chimica Acta 2008;390:1-11.

13 Cheng M, Ho H, Wu Y, Chiu DTY: Glucose-6-phosphate dehydrogenase-deficient cells show an increased propensity for oxidant-induced senescence. Free Radic Biol Med 2004;36:580-591. 


\section{Cellular Physiology Cell Physiol Biochem 2021;55:761-772 \begin{tabular}{ll|l} 
and Bioc $10.33594 / 000000474$ & 2021 The Author(s). Published by
\end{tabular} and BiOChemistry Published online: 11 December 2021 Cell Physiol Biochem Press GmbH\&Co. KG \\ Bouguerra et al.: Eryptosis in G6PD Deficiency}

14 Corash L, Spielberg S, Bartsocas C, Boxer L, Steinherz R, Sheetz M, Egan M, Schlessleman J, Schulman JD: Reduced Chronic Hemolysis during High-Dose Vitamin E Administration in Mediterranean-Type Glucose-6Phosphate Dehydrogenase Deficiency. N Engl J Med 1980;303:416-420.

15 Childs B, Zinkham W, Browne E, Kimbro E, Torbert J: A genetic study of a defect in glutathione metabolism of the erythrocyte. Bull Johns Hopkins Hosp 1958;102:21-37.

16 Minucci A, Moradkhani K, Hwang MJ, Zuppi C, Giardina B, Capoluongo E: Glucose-6-phosphate dehydrogenase (G6PD) mutations database: Review of the "old" and update of the new mutations. Blood Cells Mol Dis 2012;48:154-165.

17 Nkhoma ET, Poole C, Vannappagari V, Hall SA, Beutler E: The global prevalence of glucose-6-phosphate dehydrogenase deficiency: A systematic review and meta-analysis. Blood Cells Mol Dis 2009;42:267-78.

18 Yoshida A: Human glucose 6-phosphate dehydrogenase: purification and characterization of Negro type variant (A+) and comparison with normal enzyme (B+). Biochem Genet 1967;1:81-99.

19 Town M, Bautista J, Mason P, Luzzatto L: Both mutations in G6PD A- are necessary to produce the G6PD deficient phenotype. Hum Mol Genet 1992;1:171-174.

20 Piomelli S, Corash LM, Davenport DD, Miraglia J, Amorosi EL: In vivo lability of glucose-6-phosphate dehydrogenase in GdA- and Gdmediterranean deficiency. J Clin Invest 1968;47:940-948.

21 Föller M, Huber SM, Lang F: Erythrocyte programmed cell death. IUBMB Life 2008;60:661-668.

22 Bosman GJCGM, Willekens FLA, Werre JM: Erythrocyte Aging: A More than Superficial Resemblance to Apoptosis? Cell Physiol Biochem 2005;16:1-8.

23 Bogdanova A, Makhro A, Wang J, Lipp P, Kaestner L: Calcium in Red Blood Cells-A Perilous Balance. Int J Mol Sci 2013;14:9848-9872.

24 Lang KS, Duranton C, Poehlmann H, Myssina S, Bauer C, Lang F, Wieder T, Huber SM: Cation channels trigger apoptotic death of erythrocytes. Cell Death Differ 2003;10:249-256.

25 Daugas E, Candé C, Kroemer G: Erythrocytes: Death of a mummy. Cell Death Differ 2001;8:1131-1133.

26 Mandal D, Mazumder A, Das P, Kundu M, Basu J: Fas-, Caspase 8-, and Caspase 3-dependent Signaling Regulates the Activity of the Aminophospholipid Translocase and Phosphatidylserine Externalization in Human Erythrocytes. J Biol Chem 2005;280:39460-39467.

27 Lang F, Abed M, Lang E, Föller M: Oxidative Stress and Suicidal Erythrocyte Death. Antioxid Redox Signal 2013;21:138-153.

28 Schneider J, Nicolay JP, Föller M, Wieder T, Lang F: Suicidal Erythrocyte Death Following Cellular K+ Loss. Cell Physiol Biochem 2007;20:35-44.

29 Connor J, Pak CC, Schroit AJ: Exposure of phosphatidylserine in the outer leaflet of human red blood cells. Relationship to cell density, cell age, and clearance by mononuclear cells. J Biol Chem 1994;269:2399-2404.

30 Nguyen DB, Wagner-Britz L, Maia S, Steffen P, Wagner C, Kaestner L, Bernhardt I: Regulation of Phosphatidylserine Exposure in Red Blood Cells. Cell Physiol Biochem 2011;28:847-856.

31 Fadok VA, Savill JS, Haslett C, Bratton DL, Doherty DE, Campbell PA, Henson PM: Different populations of macrophages use either the vitronectin receptor or the phosphatidylserine receptor to recognize and remove apoptotic cells. J Immunol 1992;149:4029-4035.

32 Bratosin D, Mazurier J, Slomianny C, Aminoff D, Montreuil J: Molecular mechanisms of erythrophagocytosis: Flow cytometric quantitation of in vitro erythrocyte phagocytosis by macrophages. Cytometry 1997;30:269-274.

33 Lang K, Roll B, Myssina S, Schittenhelm M, Scheel-Walter HG, Kanz L, Fritz J, Lang F, Huber S, Wieder T: Enhanced Erythrocyte Apoptosis in Sickle Cell Anemia, Thalassemia and Glucose-6-Phosphate Dehydrogenase Deficiency. Cell Physiol Biochem 2002;12:365-372.

34 Halliwell B: Red cell metabolism. FEBS Let 1985;190:173-179.

35 Jemaà M, Fezai M, Bissinger R, Lang F: Methods Employed in Cytofluorometric Assessment of Eryptosis, the Suicidal Erythrocyte Death. Cell Physiol Biochem 2017;43:431-444.

36 Sambrook J, Russell DW: Purification of Nucleic Acids by Extraction with Phenol:Chloroform. CSH Protoc 2006; DOI:10.1101/pdb.prot4455.

37 Fang Z, Jiang C, Tang J, He M, Lin X, Chen X, Han L, Zhang Z, Feng Y, Guo Y, Li H: A comprehensive analysis of membrane and morphology of erythrocytes from patients with glucose-6-phosphate dehydrogenase deficiency. J Struct Biol 2016;194:235-243. 


\section{Cellular Physiology Cell Physiol Biochem 2021;55:761-772}

\begin{tabular}{ll|l} 
and Biochemistry & $\begin{array}{l}\text { DOl: 10.33594/000000474 } \\
\text { Published online: 11 December } 2021\end{array}$ & $\begin{array}{l}\text { C 2021 The Author(s). Published by } \\
\text { Cell Physiol Biochem Press GmbH\&Co. KG }\end{array}$ \\
\cline { 2 - 3 } & Bom
\end{tabular}

Bouguerra et al.: Eryptosis in G6PD Deficiency

38 Hertz L, Huisjes R, Llaudet-Planas E, Petkova-Kirova P, Makhro A, Danielczok JG, Egee S, del Mar MañúPereira M, Van Wijk R, Vives Corrons JL, Bogdanova A: Is Increased Intracellular Calcium in Red Blood Cells a Common Component in the Molecular Mechanism Causing Anemia? Front Physiol 2017;8:673.

39 Arese P, Gallo V, Pantaleo A, Turrini F: Life and Death of Glucose-6-Phosphate Dehydrogenase (G6PD) Deficient Erythrocytes - Role of Redox Stress and Band 3 Modifications. Transfus Med Hemother 2012;39:328-334.

40 De Jong K, Rettig MP, Low PS, Kuypers FA: Protein kinase C activation induces phosphatidylserine exposure on red blood cells. Biochemistry 2002;41:12562-125627.

41 Mandal D, Moitra PK, Saha S, Basu J: Caspase 3 regulates phosphatidylserine externalization and phagocytosis of oxidatively stressed erythrocytes. FEBS Let 2002;513:184-188.

42 Gómez-Gallego F, Garrido-Pertierra A, Mason PJ, Bautista JM: Unproductive folding of the human G6PDdeficient variant A-. FASEB J 1996;10:153-158.

43 Sirdah MM, Shubair ME, Al-Kahlout MS, Al-Tayeb JM, Prchal JT, Reading NS: Possible association of 3' UTR +357 A>G, IVS11-nt 93 T>C, c.1311 C>T polymorphism with G6PD deficiency. Hematology 2017;22:370374. 